\title{
PENGARUH PERGAULAN TERHADAP PRESTASI BELAJAR KIMIA SISWA SMA KOTA JAYAPURA
}

\author{
(Catur F. Djarwo, Alex A. Lepa) \\ Dosen Program Studi Pendidikan Kimia FKIP Universitas Cenderawasih
}

\begin{abstract}
This research aims to know the lowest and highest values of students' chemical achievement, as well as the influence of associationto chemical achievement of senior high school students in jayapura city.The type of the research was non-experimental by describing the data obtained.Techniques used in data collection ie questionnaire, observation, and documentation. The object of this research were the pupil of high school students of Jayapura Cityin a total of 52 .

The lowest student chemistry report score is 75 and the highest is 95 . The analysis used is statistical test SPSS Version 16.0. Theresult of research shows that association influences towardschemical learning achievement.
\end{abstract}

Keywords: Influence, Association, Student, Chemical Learning Achievement.

Abstrak Tujuan penelitian ini untuk mengetahui nilai terendah dan tertinggi dari prestasi belajar kimia siswa, serta pengaruh pergaulan terhadap prestasi belajar kimia siswa belajar kimia siswa SMA di Kota Jayapura.Penelitian ini merupakan penelitian noneksperimen dengan mendeskripsikan data yang diperoleh.Teknik yang digunakan dalam pengumpulan data yakni angket, observasi, dan dokumentasi.Populasi penelitian ini adalah siswa SMA Kota Jayapura yang berjumlah 52 orang.

Data nilai rapor kimia siswa yang terendah adalah 75 dan tertinggi adalah 95.Analisis yang digunakan adalah uji statistik SPSS Versi16.0.Hasil penelitian menunjukkan bahwa pergaulan teman sebaya berpengaruh terhadap prestasi belajar kimia.

Kata Kunci:Pengaruh, Pergaulan, Siswa, Prestasi Belajar Kimia. 


\section{PENDAHULUAN}

\section{LATAR BELAKANG}

Undang-undang RI Nomor 20 Tahun 2003 Pasal 1 Ayat 20 tentang Sistem Pendidikan Nasional menuliskan bahwa pembelajaran adalah proses interaksi siswa (peserta didik) dengan pendidik dan sumber belajar pada suatu lingkungan belajar.Interaksi antar siswa dapat mempengaruhi hubungan atau pergaulan yang dapat membentuk kepribadian seseorang.

Pergaulan adalah jalinan hubungan sosial antara seseorang dengan orang lain sehingga terjadi saling mempengaruhi satu dengan lainnya (Suryabrata, 2001: 32).Pengaruh dari individu atau kelompok dapat berdampak positif atau negatif terhadap kepribadian seseorang. Dampak positif berupa kerja sama antar individu atau kelompok yang bermanfaat sedangkan dampak negatif dapat mengarahkan seseorang pada pergaulan bebas yang harus dihindari oleh setiap masyarakat khususnya bagi remaja (Papalia \& Feldman, 2014: 366).
Remaja (adolescene) diartikan sebagai masa perkembangan transisi antara masa anak dan masa dewasa yang mencakup perubahan biologis, kognitif, dan sosialemosional(Santrock, 2003: 26).Menurut Asrori (2015: 40) Kognitif adalah proses psikologis di dalamnya melibatkan proses memperoleh, menyusun dan menggunakan pengetahuan. Pengetahuan adalah segala sesuatu yang diketahui berkenaan dengan mata pelajaran (Poerwadarminta, 2011: 866).Salah satu mata pelajaran yang diajarkan di Sekolah Menengah Atas adalahIlmu Kimia.

Materi ilmu kimia dimulai dari konsep yang sederhana hingga yang lebih kompleks dan mempunyai tingkat kesulitan yang tinggi sehingga menyebabkan siswa kurang tertarik, hal ini didukung oleh penelitian yang dilakukan oleh Nazhifah, dkk yang menunjukkan 54\% siswa SMA Negeri 9 Pekanbaru dari 246 responden menganggap pelajaran kimia sebagai pelajaran yang sulit, membosankan, dan kurang bermanfaat.Ketertarikan yang kurang terhadap ilmu kimia 
menyebabkan siswa mencari kegiatan lain seperti menjalin hubungan antar siswa yang tidak berhubugan dengan pelajaran kimia. Menjalin hubungan yang tidak membahas tentang pelajaran dapat memberi pengaruh positif ataupun pengaruh negatif. Pengaruh positif akanmemberikan dorongan dalam belajar, baik disekolah maupun di luar sekolah, sehingga akan berdampak pada hasil belajar yang diperoleh dan pengaruh negatif adalah penggunaan narkoba, perilaku seks bebas, dan melakukan tindak kriminal.

\section{TINJAUAN PUSTAKA}

\section{Pengertian Prestasi Belajar}

Prestasi belajar menurut Kamus Besar Bahasa Indonesia (2005: 895) adalah Penguasaan pengetahuan atau keterampilan yang dikembangkan oleh mata pelajaran, lazimnya ditunjukkan dengan nilai tes atau angka nilai yang diberikan guru dan kemampuan yang sungguh-sungguh ada atau dapat diamati (actual ability) dan yang dapat diukur langsung dengan tes tertentu.

Menurut Suryabrata (2006: 297), prestasi didefinisikan sebagai nilai yang merupakan perumusan terakhir yang dapat diberikan oleh guru mengenai kemajuan atau prestasi belajar siswa selama masa tertentu. Berdasarkan uraian diatas dapat dikatakan bahwa prestasi belajar adalah usaha yang dicapaioleh siswa dengan melibatkan seluruh potensi yang dimilikinya setelah siswa tersebut melakukan kegiatan belajar.Pencapaian hasil belajar tersebut dapat diketahui dengan mengadakan penilaian tes hasil belajar.Penilaian diadakan untuk mengetahui sejauh mana siswa telah berhasil mengikuti pelajaran yang diberikan oleh guru.

\section{Faktor-Faktor yang Mempengaruhi}

\section{Prestasi Belajar}

Ngalim (2010: 107)menyatakan faktor-faktor yang mempengaruhi prestasi belajar adalah faktor dari dalam diri individu terdiri dari faktor fisiologis dan faktor psikologis.Faktor fisiologis adalah kondisi jasmani dan kondisi panca indera sedangkan faktor psikologis adalah bakat, minat, kecerdasan, dan kemampuan kognitif.Faktor dari luar individu terdiri dari faktor lingkungan dan faktor instrumental.Faktor lingkungan 
adalah lingkungan sosial di mana seseorang berada pada lingkungan keluarga, sekolah, masyarakat, dan kelompok, sedangkan faktor instrumenal yaitu kurikulum, bahan, guru, sarana, administrasi.

\section{Ilmu Kimia}

Ilmu kimia adalah ilmu yang mempelajari tentang susunan, struktur, sifat, perubahan serta energi yang menyertai perubahan suatu zat atau materi Zat atau materi adalah segala sesuatu yang menempati ruang dan mempunyai massa (Syarifudin, 2008: 1).

Ilmu kimia disebut juga central science, karena memiliki peranan yang sangat penting di antara ilmu pengetahuan lain. Semua bidang ilmu bergantung pada ilmu kimia.Pengembangan dalam bidang kedokteran, farmasi, geologi, pertanian dan sebagainya, tak mungkin terjadi tanpa kemajuan yang dicapai dalam ilmu kimia. Dunia pendidikan menjadikan kimia sebagai ilmu sentral, karena dalam pelajaran biologi, geologi dan fisika akan menemukan topik yang menyangkut tentang ilmu kimia (Sudarmo, 2009: 5).

\section{Remaja}

Asrori (2015: 13) berpendapat bahwa remaja berasal dari bahasa latin "adolescere" yang artinya "tumbuh atau tumbuh untuk mencapai kematangan." Masa remaja dibagi menjadi tiga bagian, yakni usia 12/13 tahun sampai dengan 14/15 tahun remaja awal, usia 15/16 tahun sampai dengan 17/18 tahun adalah remaja tengah, dan usia 18/19 tahun sampai dengan 21/22 tahun adalah remaja akhir. Ratrioso (2008: 15) menyebutkan remaja adalah usia dimana individu berintegrasi dengan masyarakat dewasa, usia dimana anak tidak lagi merasa di bawah tingkat orang-orang yang lebih tua melainkan berada dalam tingkatan yang sama. Berdasarkan pengertian tersebut dapat disimpulkan bahwa remaja adalah masa peralihan dari masa anak-anak dengan masa dewasa, dimana pada masa tersebut terjadi proses pematangan baik itu pematangan fisik, maupun psikologis. 


\section{Pergaulan}

Hadi (2008: 63) berpendapat bahwa pergaulan adalah kontak langsung antara satu individu dengan individu lain, termasuk di dalamnya pendidik dan siswa. Ahmadi dan Uhbiyati (2007: 1) mengemukakan pergaulan adalah kontak langsung antara satu individu dengan individu lain. Berdasarkan pernyataan-pernyataan di atas, didapat suatu kesimpulan bahwa yang dimaksud dengan pergaulan adalah hubungan atau interaksi antara seseorang dengan orang lain yang meliputi tingkah laku dan melibatkan orang lain.

\section{TUJUAN PENELITIAN}

Tujuan dari penelitian ini adalah untuk mengetahui nilai terendah dan tertinggi dari prestasi belajar kimia siswa dan menganalisis besar pengaruh pergaulan terhadap prestasi belajarkimia siswa belajar kimia siswa SMA di Kota Jayapura.

\section{METODOLOGI PENELITIAN}

\section{Jenis Penelitian}

Sifat penelitian ini adalah noneksperimen dengan mendeskripsikan data-data yang diperoleh dalam penelitian ini dari angket yang diberikan kepada siswa SMA Kota Jayapura.

\section{Variabel Penelitian}

Variabel dalam penelitian ini adalah:

Variabel bebas adalah pergaulan

Variabel terikat adalah prestasi belajar siswa

\section{Populasi}

Siswa-siswi di Sekolah Menengah Atas Kota Jayapurasebagai populasi dalam penelitian ini.

\section{Teknik Pengumpulan Data}

Penelitian ini menggunakan teknik pengumpulan data yang berupahasil angket, observasi serta data dokumentasiyang diuraikan sebagai berikut:

\section{Angket}

Angket adalah daftar pertanyaan atau pernyataan yang diberikan kepada orang lain yang bersedia memberikan respons (responden) sesuai dengan permintaan pengguna(Riduwan, 2009: 99). Tujuan dari angket untuk memperoleh data atau informasi tentang pengaruh pergaulan terhadap prestasi belajar kimia siswaSMA Kota Jayapura. 


\section{Observasi}

Observasi yaitu melakukan

pengamatan secara langsung ke objek penelitian untuk melihat dari dekat kegiatan yang dilakukan siswa(Riduwan, 2009:104).Tujuan observasi yaitu untuk melihat keadaan siswa dan keadaan lingkungan sekolah.

\section{Dokumentasi}

Dokumentasi digunakan untuk melengkapi pengambilan data.Teknik pengumpulan dokumentasi bertujuan untuk memperoleh data nilai rapor kimiasiswa SMA Kota Jayapura, yang digunakan untuk membuktikan pengaruh pergaulan terhadap prestasi belajar kimia.

\section{Teknik Analisis Data}

Tahap pengambilan data menggunakan angket, observasi dan dokumentasi kemudian menghasilkan data-data. Data yang diperoleh kemudian dianalisis dengan analisis deskriptif, yaitu dengan cara mendeskripsikan atau menggambarkan pengaruh pergaulan terhadap prestasi belajar kimia pada siswa SMA Kota Jayapura. Teknik analisis data yang digunakan dalam penelitian berupa uji statistik dengan menggunakan bantuan aplikasi Statistical, Product, \& Service Solution (SPSS) versi 16.0 proses analisis sebagai berikut :

\section{Uji normalitas}

Uji normalitas digunakan untuk mengetahui normal tidaknya data.Analisis data yang digunakan dalam penelitian ini menggunakan metode kolmogorov-smirnov, dengan ketentuan asymp. Sig (2-tailed)> 0,05 maka $\mathrm{H}_{\mathrm{a}}$ diterima sehingga data dikatakan normal, sebaliknya apabila, asymp. Sig (2-tailed) $<0,05$ maka $\mathrm{H}_{0}$ ditolak berarti data tidak berdistribusi normal.

\section{Menghitung Harga Korelasi Mencari persamaan regresi}

Untuk mengetahui hubungan Variabel $\mathrm{X}$ dan Variabel Y berbentuk linier atau tidak digunakan analisis regresi. Untuk itu perlu dibuat persamaan garis regresi dengan menggunakan rumus:

$\widehat{Y}=a+b x$

Sedangkan untuk memperoleh nilai a dan $b$ digunakan rumus sebagai berikut:

$$
\begin{aligned}
a & =\frac{\left(\sum Y\right)\left(\sum X^{2}\right)-\left(\sum X\right)\left(\sum X Y\right)}{N \sum X^{2}-\left(\sum X\right)^{2}} \ldots \ldots . .(2) \\
b & =\frac{N \sum Y-\left(\sum X\right)\left(\sum Y\right)}{N \sum X^{2}-\left(\sum X\right)^{2}} \ldots \ldots(3)
\end{aligned}
$$


(Sudjana, 2005: 315)

\section{Uji Kebergantungan}

Untuk mengetahui apakah variabel y bergantung pada variabel $\mathrm{x}$ digunakan analisis varians. Adapun rumus yang digunakan adalah:

$J K\left(\frac{a}{b}\right)=b\left[\sum X Y-\frac{\left(\sum X\right)\left(\sum Y\right)}{N}\right] \ldots$.

Dengan kriteria pengujian :

$\mathrm{H}_{0}=$ Prestasi belajar tidak bergantung terhadap pergaulan

$\mathrm{H}_{\mathrm{a}}=$ Prestasibelajar bergantung terhadap pergaulan

$\mathrm{H}_{0}$ ditolak jika $\mathrm{F}_{\text {hitung }} \geq \mathrm{F}_{\text {tabel }}$

(Sudjana, 2005: 330)

\section{Uji Kelinieran}

Untuk menguji kelinieran digunakan analisis variasi dengan rumus sebagai berikut:

$\mathrm{JK}(\mathrm{E})=\sum_{n}\left(\sum y^{2}-\frac{\sum y^{2}}{N}\right) \ldots \ldots .(5)$

$\mathrm{JK}(\mathrm{TC})=\mathrm{JK}($ residu $)-\mathrm{JK}(\mathrm{E}) \ldots . .(6)$

\section{Uji Korelasi}

Untuk mengetahui pengaruh pergaulan terhadap prestasi belajar digunakan rumus $r$ (product moment) sebagai berikut :

$r_{x y}=\frac{N \Sigma X Y-(\Sigma X)(\Sigma Y)}{\sqrt{\left\{N \Sigma X^{2}-(\Sigma X)^{2}\right\}\left\{N \Sigma Y^{2}-(\Sigma Y)^{2}\right\}}} \ldots$ (7)

(Arikunto, 2006: 243)
Dimana :

$\mathrm{r}_{\mathrm{xy}}$ :Koefisien Korelasi antara X dan Y

$\mathrm{X}$ : Variabel Bebas

Y: Variabel Terikat

\section{Uji Determinasi}

Untuk mengetahui pengaruh variabel $\mathrm{X}$ terhadap variabel $\mathrm{Y}$ digunakan rumus sebagai berikut:

$\mathrm{r}^{2}=\frac{\left[\sum(\mathrm{X}-\bar{X})-(\mathrm{Y}-\bar{Y})\right]^{2}}{\left.\sum(\mathrm{X}-\bar{X})^{2}-\sum(\mathrm{Y}-\bar{Y})\right]^{2}} \ldots . .(8$

Keterangan :

$\mathrm{r}^{2}=$ koefisien determinasi(Sudjana, 2005: 368)

\section{Menentukan besarnya pengaruh}

Besarnya pengaruh antara variabel $\mathrm{Y}$ terhadap variabel $\mathrm{X}$ dapat dilihat dari harga $r^{2}$ ( $r$ adalah koefisien korelasi), di $\operatorname{manar}^{2}=$ koefisien determinasi untuk mengetahui persentase besarnya pengaruh, digunakan persamaan

$\%=\mathrm{r}^{2} .100$

(Sudjana, 2005: 370)

\section{HASIL PENELITIAN DAN PEMBAHASAN}

\section{Hasil Penelitian}

Hasil penelitian menunjukkan terdapat 3 kategori nilai pergaulan yaitu rendah, sedang dan tinggi. Kategori nilai pergaulan dan rata-rata nilai rapor 
kimia yang diperoleh siswa berbedabeda yakni pada kategori nilai pergaulan rendah terdapat $3,8 \%$ siswa dengan rentang nilai pergaulan yang diperoleh 38,38-39,06 dan rata-rata nilai rapor kimia adalah 75 , kategori nilai pergaulan sedang $42,3 \%$ siswa dengan rentang nilai pergaulan $41,75-$ 60,27 dan rata-rata nilai rapor kimia 78,59 , kategori nilai pergaulan tinggi $53,8 \%$ siswa dengan rentang nilai pergaulan 61,28-79,46 dan rata-rata nilai rapor kimia 83. Nilai pergaulan tertinggi yang diperoleh siswa sebesar 79,46 dan terendah 38,38 sedangkan nilai rapor kimia siswa yang tertinggi adalah 95 dan terendah 75 .

\section{Pembahasan}

Berdasarkan data dan analisis data yang telah peneliti lakukan, maka peneliti dapat menyimpulkan bahwa pergaulan mempengaruhi prestasi belajar yang dipengaruhi oleh kerjasama yang baik antar sahabat atau teman, dan saling menolong dalam hal belajar.

Indikator yang pertama yang dianalisis adalah persahabatan. Persahabatan memiliki tiga sub indikator yakni waktu, membantu, dan dukungan.
Hasil menunjukkan bahwa sebagian siswa terkadanglebih memilih menyiapkan waktu untuk belajar kimia daripada pergi dengan teman.Keakraban antar beberapa siswa dengan teman dikarenakan sebagian siswa akan dibantu saat kesulitan belajar khususnya dalam memahami materi kimia.Keakraban juga terjalin antara beberapa siswa dan guru dimana guru lebih banyak membantu menjelaskan saat siswa merasa kesulitan memahami materi kimia dan memberikan dorongan kepada siswa untuk mengerjakan PR.Selain guru, sebagian besar orangtua mengutamakan anaknya mengerjakan PR daripada menyuruh menyelesaikan pekerjaan rumah.

Indikator yang kedua adalah tingkah laku yang memiliki lima sub indikator yakni ingatan, tanggapan, terpengaruh, kesan, dan sadar. Hasil menunjukkan bahwa saat proses pelajaran kimia sedang berlangsung siswa lebih terfokus pada pelajaran kimia terbukti pada persentase terbesar adalah siswa yang tidak pernah mengingat pacar. Sebagian siswa juga ada yang berangan-angan ingin berteman 
dengan orang yang berprestasi tinggi pada pelajaran kimia dikarenakan siswa lebih mudah bertanya materi saat merasa kesulitan pada pelajaran kimia.

Indikator yang ketiga adalah kontak langsung yang memiliki lima sub indikator dan salah satu indikatornya adalah niat yang menunjukkan bahwa sebagian kecilsiswa mempunyai niat bolos pada jam pelajaran kimia, hal ini menandakan bahwa siswa tidak mudah terpengaruh saat diajak untuk bolos bersama. Teman yang selalu mendapat nilai PR dan ulangan kimia yang baik menyebabkan sebagian besar siswa mempunyai niat agar memperoleh nilai yang sama untuk mendapat hasil yang baik pada pelajaran kimia.

Selain pergaulan, faktor lain yang mempengaruhi prestasi belajar kimia yaitu faktor internal dan faktor eksternal. Faktor internal adalah faktor yang berasal dari dalam diri siswa yang meliputi kecerdasan, bakat, minat, kemampuan kognitif, kondisi jasmani dan kondisi panca indera sedangkan faktor eksternal yaitu faktor yang berasal dari luar diri siswa yang meliputi lingkungan keluarga, status sosial ekonomi, sarana, fasilitas dan metode mengajar guru.

\section{KESIMPULAN DAN SARAN}

\section{Kesimpulan}

Berdasarkan penelitian yang dilakukan dapat disimpulkan bahwa:

1. Nilai kimia terendah siswa SMA Kota Jayapura adalah 75 dan tertinggi adalah 95.

2. Terdapat pengaruh pergaulan terhadap prestasi belajar kimia siswa SMA Kota Jayapura.

\section{Saran}

Berdasarkan hasil penelitian, saran yang dapat peneliti berikan yaitu:

1. Siswa sebaiknya pandai dalam memilih teman bergaul agar dapat meningkatkan prestasi belajar.

2. Lingkungan pergaulan anak di luar rumah dan sekolah ternyata terbukti berpengaruh terhadap prestasi belajar siswa, oleh karena itu orang tua dan guru hendaknya memperhatikan dengan siapa siswa bergaul agar tidak terjerumus ke pergaulan negatif.

\section{DAFTAR PUSTAKA}

Ahmadi, A \& Uhbiyati, N (2007).Ilmu Pendidikan. Jakarta: Rineka Cipta. 
Asrori, H. M. (2015). Perkembangan Siswa ; Pengembangan Kompetensi

Pedagogis Guru. Yogyakarta: media akademi.

Hadi, A. S. (2008). Pendidikan (Suatu Pengantar). Surakarta: UNS Press.

Ngalim Purwanto. (2010). Prinsipprinsip dan Teknik Evaluasi Pengajaran. Jakarta: PT Remaja Rosdakarya.

Papalia, Diane E. \& Feldman, Ruth Duskin. (2014). Menyelami Perkembangan

Manusia. Jakarta: Salemba Humanika.

Poerwadarminta. (2011). Kamus Umum Besar Bahasa Indonesia. Jakarta: Balai Pustaka.

Poerwadarminta. (2011). Kamus Umum Besar Bahasa Indonesia. Jakarta: Balai Pustaka.

Ratrioso, i. (2008). Remaja Unggul. Jakarta: Nobel Edumedia.

Riduwan.(2009). Metode dan teknik Menyusun Instrumen. Bandung: Alfabetis.

Santrock, John W. (2003). Perkembangan Remaja, Edisi Keenam, Jilid Dua. (Alihbahasa: Mila Rachmawati dan Anna Kuswanti). Jakarta: Penerbit Erlangga.

Sudarmo, Unggul. (2009). Kimia untuk SMA kelas $X$. Jakarta: PHißETA.

Sudjana. (2005). Metode Statistika. Bandung: PT. Tarsito.

Suryabrata, Sumadi. (2001). Psikologi Pendidikan.Jakarta: Rakel Pers.
Suryabrata, Sumadi. (2006). Psikologi Pendidikan. Jakarta: PT Raja Grafindo Persada.

Syarifudin. (2008). Inti Sari Kimia untuk SMA. Tangerang: Scientific Press.

Tim Penyusun Kamus Besar Bahasa Indonesia.(2005). Kamus Besar Bahasa Indonesia.Departemen Pendidikan dan Kebudayaan. Jakarta: Balai Pustaka.

Undang-Undang nomor 20.(2003). Sistem Pendidikan Nasional.Kementerian Pendidikan Nasional. 